\title{
AS INSTITUIÇÕES ENTRE AS ESTRUTURAS E AS AÇÕES*
}

BRUNO THÉRET

O institucionalismo, que passa por uma fase de renovação em todas as ciências sociais, distingue-se de outros paradigmas intelectuais, especialmente as ortodoxias do individualismo metodológico, ao apontar para a necessidade de se levar em conta, a fim de se compreender a ação dos indivíduos e suas manifestações coletivas, as mediações entre as estruturas sociais e os comportamentos individuais. Essas mediações são precisamente as instituições.

Por outro lado, se seguíssemos Paul DiMaggio e Walter Powell, acreditaríamos que "o institucionalismo tem sentidos variados dependendo das disciplinas", sendo difícil de defini-lo positivamente, na medida em que "os acadêmicos que trabalham sobre instituições geralmente concederam pouca atenção à sua definição". Isso em razão que os "diversos institucionalismos - em Economia, teoria das organizações, Ciência Política, public choice, História e Sociologia - (...) aproximam-se apenas pelo mesmo ceticismo que revelam a respeito das concepções atomísticas dos processos sociais e pela crença difusa de que os dispositivos institucionais e os processos sociais são importantes".

Um ponto de vista como esse deve ser fortemente nuançado. Com efeito, pode-se encontrar definições precisas de instituições, e teremos a oportunidade de fornecê-las ao longo do texto, tanto entre economistas como entre sociólogos, tanto entre antigos como entre novos institucionalistas. É mesmo baseada nessas definições que se estabelecem

* "Vers une convergence intra-et interdisciplinaire des conceptios de l'institution?" Comunicação no Colóquio "Organizations et institutions: régles, coordination et evolution", maio de 2001. Tradução de Bernardo Ricupero. 
as fronteiras entre as abordagens, as diferenças podendo mesmo ser maiores no interior das disciplinas que ente elas. Assim, os próprios DiMaggio e Powell observam que no interior da teoria das organizações, “os 'institucionalistas' diferenciam-se a partir da ênfase que atribuem ao caráter micro ou macro dos fenômenos institucionais, ao peso que imputam nos aspectos cognitivos ou normativos das instituições, e à atenção que dispensam aos interesses e às redes de relações na criação e difusão das instituições".

É possível, portanto, encontrar, tanto em Ciência Política como em Economia e Sociologia, um mesmo desenvolvimento básico do institucionalismo, que se divide em três grandes correntes, cada uma possuindo sua própria genealogia. Essa estrutura tripolar é encontrada na teoria econômica francesa na forma da teoria da regulação, na nova economia institucional e na economia das convenções. Por outro lado, observa-se que para além de suas próprias filiações teóricas, esses diversos institucionalismos não deixam de influenciar disciplinas particulares. Analisadas em comum, elas possuem características coincidentes e influências mútuas que as conduzem a desenvolvimentos mais convergentes do que divergentes e resultam no que começa a ser chamado de um "holindividualismo" (Defalvard, 1992). Dentro dessa tendência, os novos institucionalistas começam a revalorizar o primeiro institucionalismo, o dos fundadores da Sociologia européia e da Economia institucionalista norte-americana.

Este texto enfatiza precisamente as tendências que influenciam a dinâmica interna da Ciência Política, da Economia e da Sociologia, como disciplinas separadas, e as relações entre esses três campos. Com esse objetivo, mostraremos, inicialmente, que independentemente das disciplinas, os novos institucionalismos se diferenciam a partir de duas grandes oposições: 1) o peso que atribuem na gênese das instituições aos conflitos de interesse e de poder ou à coordenação entre indivíduos; 2) o papel que imaginam que desempenham na relação entre as instituições e no comportamento dos atores a racionalidade instrumental calculadora ou as representações e a cultura. A recorrência dessas oposições indica a existência de uma configuração ternária nos atuais paradigmas institucionalistas, que transcende as fronteiras das disciplinas das ciências sociais. Num segundo momento, examina-se a dinâmica intradisciplinar que leva esses diferentes paradigmas a terem encontros, e até mesmo diálogos, o que, na medida em que cada um deles é marcado por uma origem científica específica, conduz igualmente a uma convergência transdisciplinar, ao "holindividualismo", que recoloca na ordem do dia o pensamento institucionalista original. 


\section{OS TRÊS NOVOS INSTITUCIONALISMOS}

Diversos trabalhos recentes propõem-se a traçar o mapa das variações interdisciplinares e transdisciplinares que marcam o desenvolvimento recente do institucionalismo. Fornecem um ponto de partida útil para refletir sobre os diferentes significados assumidos pela noção de instituição, na medida em que não prestam especial atenção às fronteiras entre os variados enfoques, o que não é muito comum no concorrido campo intelectual. Também pretendem demonstrar as similaridades e mesmo as evoluções convergentes entre os enfoques. No entanto, esses trabalhos partem ou da diversidade dos institucionalismos presentes nas diversas disciplinas (DiMaggio, Powell, 1997), ou, ao contrário, de sua variedade no interior de uma mesma disciplina (Hall, Taylor, 1996; Immergut, 1996). Ao fazerem isso, passam à margem de um aspecto importante da questão, a redundância das diferenciações entre uma disciplina e outra, redundância que testemunha a ocorrência de convergência entre disciplinas e não apenas nas interfaces de correntes presentes em cada uma delas.

\section{O institucionalismo em Ciência Política}

Foi na Ciência Política, com o trabalho de Peter Hall e Rosemary Taylor $^{1}$, que surgiu a preocupação de avaliar a variedade de novos institucionalismos presentes no interior de uma mesma disciplina. $\mathrm{O}$ trabalho anterior (1991) de DiMaggio e Powell (1997) preocupava-se, por sua vez, em distinguir as modalidades de institucionalismo utilizadas nas variadas disciplinas, considerando que cada uma delas - a Economia com a nova economia institucional, a Ciência Política com a teoria da escolha racional e a Sociologia com a teoria das organizações - privilegiava uma variedade específica de institucionalismo. A grande contribuição de Hall e Taylor, reforçada pelo trabalho de Ellen Immergut, está em mostrar que, na verdade, desenvolveram-se em Ciência Política três novos institucionalismos e não apenas um. São eles: um institucionalismo histórico, um institucionalismo da escolha racional e um institucionalismo sociológico.

Hall e Taylor constróem analiticamente a distinção entre esses três institucionalismos a partir de duas questões: Como esses enfoques encaram a relação entre instituições e comportamentos individuais? Como vêem o processo de formação e transformação das instituições?

\footnotetext{
${ }^{1}$ Publicado neste número de Lua Nova.
} 
Respondem à primeira questão distinguindo duas formas como a relação entre instituições e comportamento são entendidas, de acordo com um "enfoque de cálculo" e um "enfoque cultural" (Hall, Taylor, 1996). O enfoque de cálculo, presente apenas no institucionalismo da escolha racional, enfatiza o caráter instrumental e estratégico do comportamento. Nessa perspectiva, as instituições têm sobre o comportamento do indivíduo o efeito de reduzir a incerteza em relação a como será a ação dos outros. $\mathrm{O}$ enfoque cultural, privilegiado pela teoria das organizações (na base do institucionalismo sociológico), enfatiza, ao contrário, a dimensão rotineira do comportamento e o papel desempenhado pela visão de mundo do ator na interpretação de situações. ${ }^{2}$ Nesse caso, as instituições corresponderiam aos "planos morais e cognitivos de referência sobre os quais são baseadas a interpretação da ação". Não é difícil de perceber que os dois enfoques entendem a mudança institucional de maneira oposta.

Na concepção puramente estratégica, de cálculo, as instituições são vistas como o resultado intencional, quase contratual, e funcional de estratégias de otimização de ganho por parte dos agentes. Elas podem, consequentemente, mudar de natureza depois que tenham desempenhado seu papel. Ao contrário, para a concepção "cultural”, baseada em níveis de percepção e em comportamentos rotineiros, as instituições são a tal ponto convencionais que quase escapam à análise; resistiriam à mudança até porque estruturariam mesmo as escolhas individuais visando a reforma.

$\mathrm{O}$ institucionalismo histórico se distingue dos demais em razão de ser "eclético" em relação a esse primeiro critério metodológico, misturando os enfoques: os atores calculariam com base em seus interesses, mas ao mesmo tempo possuiriam diferentes visões de mundo, correspondentes às suas posições e contextos sociais - consequentemente, os interesses não seriam dados, como as preferências no institucionalismo da escolha racional, mas construídos politicamente (Immergut, 1996). ${ }^{3}$ Cálculo e cultura se combinariam para formar atores coletivos, que agiriam no plano de

2 Cf. igualmente (DiMaggio, Powell, 1997, p. 127). Veremos que a cultura em questão não é entendida simplesmente como um conjunto de valores e atitudes compartilhadas, mas correspondendo, de maneira geral, à "rede de rotinas, de símbolos e de cenários que formam o quadro de referências para os comportamentos" (Hall, Taylor, 1996, p. 15).

3 Com efeito, nos EUA o institucionalismo histórico desenvolveu-se como reação ao behavorismo, forma que o individualismo metodológico assume em Ciência Política. Distinguindo preferências exprimidas de preferências reais, e encarando a agregação de preferências individuais como muito problemática, considera que os interesses não equivalem às avaliações subjetivas dos indivíduos e que as decisões coletivas não deveriam ser equiparados à soma de escolhas individuais (cf. Immergut, 1996, pp. 4-6). 
macro-instituições herdadas e com base em relações de poder assimétricas. As instituições não seriam entendidas, portanto, à maneira da teoria da ação racional, como o resultado intencional da ação de indivíduos otimizadores, apesar de não deixar de ser admitido que elas poderiam ser suscetíveis de sofrerem a influência dos interesses e dos cálculos dos atores. $\mathrm{Na}$ verdade, as instituições - particularmente o Direito e a Constituição - desempenhariam um duplo papel. Constrangeriam e desviariam o comportamento humano, mas também forneceriam os meios para a libertação das cadeias sociais".

O institucionalismo histórico também se diferencia dos outros neoinstitucionalismos devido à maneira como encara o segundo critério discriminador, relativo à gênese das instituições: as instituições surgiriam como forma de regular conflitos irredutíveis? Elas não funcionariam sobretudo como soluções para problemas de coordenação da ação humana? A essas questões, o institucionalismo histórico responde afirmando que a instituição funciona como uma maneira de regular conflitos inerentes ao desenvolvimento da diferenciação de interesses e à assimetria de poder, o que contrasta com a postura do institucionalismo sociológico e do institucionalismo da escolha racional, que a vêem como uma solução para problemas de coordenação. ${ }^{4}$ A teoria da escolha racional, por sua vez, afirma que indivíduos iguais têm preferências dadas, cujos problemas referem-se simplesmente à coordenação de ação, até porque a otimização racional do comportamento exige que se encontre uma solução para ela. O neo-institucionalismo sociológico, por sua parte, considera a coordenação por meio de dispositivos cognitivos central às organizações, ao passo que os conflitos de interesse e a luta política são vistos como "periféricos".

Em compensação, no caso da relação entre o institucionalismo sociológico e o institucionalismo histórico, a oposição referente à origem das instituições, coordenação/conflito, é reforçada pela oposição entre posturas sobre o cognitivo e o normativo. Com efeito, para o neo-institucionalismo sociológico, "a institucionalização é basicamente um processo cognitivo”. (...) Não são as normas e os valores mas os cenários, as regras

\footnotetext{
${ }^{4}$ Assim, "ao passo que os teóricos da organização (institucionalismo sociológico) enfatizam os limites da racionalidade e as vias pelas quais as regras de organização e procedimento coordenam a ação de indivíduos independentes, os institucionalistas históricos focalizam mais diretamente os temas do poder e dos interesses. (...) Em comparação com teorias da escolha racional e da organização, os pioneiros do institucionalismo histórico tenderam a assumir uma postura mais macrosociológica e orientada para a análise do poder (Immergut, 1996, p. 17). Cf. igualmente (DiMaggio, Powell, 1997, p. 128).
} 
e as classificações que constituem a matéria prima das instituições". Ao contrário, o institucionalismo histórico, como mostra Immergut (1996), tem raízes normativas, que não se pode ignorar: já que as instituições determinam as condutas individuais elas deveriam também "se perguntar para onde conduz a orientação e quais são suas implicações", além de "sugerir vias de aperfeiçoamento quanto ao caráter 'justo' dos efeitos das instituições" (Immergut, 1996). "O problema de determinar as normas substantivas para julgar os processos políticos e seus resultados é, portanto, uma questão central para a teoria institucionalista"5.

Isso posto, combinando enfim os dois critérios metodológicos de diferenciação - cálculo/cultura, conflito/coordenação -, obteremos a configuração tripolar descrita no gráfico 1 , a partir da qual os novos institucionalistas em Ciência Política diferenciam-se claramente uns dos outros, mas continuariam a manter relações bilaterais, cada uma de natureza diferente. Assim, o institucionalismo histórico e o neo-institucionalismo sociológico reencontram-se na sua crítica comum ao institucionalismo da escolha racional: na recusa de uma atitude funcionalista na definição e entendimento da gênese das instituições, ao não aceitar o exclusivismo da racionalidade instrumental como forma de explicar os comportamentos, ao descartar a idéia de uma intencionalidade pura, indo contra a monocausalidade, e na aceitação de que os resultados das ações são contingentes. Em suma, não consideram que as instituições são exógenas aos comportamentos dos indivíduos, ou melhor, à conduta dos atores sociais. Mas os dois têm divergência quanto à origem das instituições, o institucionalismo sociológico aproximando-se do institucionalismo da escolha racional numa concepção quase de individualismo metodológico e "problem-solving".

É verdade que a maneira do institucionalismo sociológico e do institucionalismo da escolha racional entenderem a solução dos problemas de coordenação é radicalmente diferente. Para o primeiro enfoque os processos

5 Veremos, entretanto, com DiMaggio e Powell, que o institucionalismo sociológico, "a despeito da passagem (...) de um enfoque normativo para um enfoque cognitivo de ação: do engajamento à rotina, dos valores às premissas, da motivação à lógica baseada em regras" (DiMaggio, Powell, 1997, p. 137), não tem posição conjunta sobre esse ponto, na medida em que tende a reconhecer, a partir de uma "importante intuição de Parsons", que a "cultura" e, também, a ação direcionada pela "razão prática", compreendem além do "domínio cognitivo (composto de idéias e crenças), uma dimensão afetiva/expressiva e um elemento valorativo (referente à orientação de valor)" (ibid., p. 134) e que "os diferentes domínios institucionais suscitam variados graus de orientações cognitivas, afetivos/valorativos" (ibid., p. 144). O que faz com que "o peso relativo da cognição, dos afetos e da valor mudem de acordo com o quadro da ação" (ibid., p. 145). 
de decisão "envolvem mais a observância de regras do que o cálculo de consequências" (DiMaggio e Powell, 1997, p. 137). Os teóricos da escolha racional, em compensação, encaram as instituições como soluções adaptadas eficazes "para os problemas da oportunidade, da informação imperfeita ou assimétrica, e dos custos de controle", resultados esses que não podem ser garantidos pelos teóricos da organização. Por fim, a maneira de entender a gênese das instituições, como problema de coordenação, é comum ao institucionalismo sociológico e o institucionalismo da escolha racional e opõe-se à forma que o institucionalismo histórico a vê como questão de regulação de conflitos de interesses. Inversamente, o institucionalismo histórico aproxima-se do institucionalismo da escolha racional, que se afasta do institucionalismo sociológico, ao prestar atenção ao cálculo estratégico dos atores, as instituições possuindo, para as duas posições, uma dimensão de libertação da ação individual e não apenas de constrangimento.

\section{Os novos institucionalismos em Economia}

Uma configuração tripolar isomorfa também aparece no campo da Economia, mesmo que ela se apresente de forma particular em diferentes casos nacionais no que se refere aos pólos não ortodoxos da disciplina. Com efeito, o institucionalismo da escolha racional também está presente na Economia sob a forma da Nova Economia Institucional, nova ortodoxia amplamente difundida pelo mundo, ao passo que:

o institucionalismo sociológico da teoria das organizações assume a forma de uma Economia das Convenções, que aparece na França nos anos 1980, e tem sua contrapartida na análise da segmentação do mercado de trabalho (M. Piore) e na teoria do salário eficaz que se desenvolvem nos EUA a partir de 1970, com H. Leibenstein e G. Akerloff (Favereau, 1989; B. Reynaud, 1992);

o institucionalismo histórico apresenta-se sob as vestes da Teoria da Regulação, que se desenvolve na França na década de 1970, e reaparece nos EUA no "neo-institucionalismo" dos herdeiros do antigo institucionalismo norte-americano, como Galbraith, Gruchy e Hodgson (Vileval, 1995, p. 480), e também entre os economistas radicais, que se aproximam do enfoque pela estudo das "estruturas sociais de acumulação", que emerge como a teoria da regulação nos anos 70 (Coban, 1995).

A análise não será, entretanto, exaustiva, focalizando apenas o caso francês, que tem a vantagem de ser bem estruturado e ser passível de 
esquematização, expressa na tríade: nova economia institucional/ economia das convenções/ teoria da regulação.

Não é preciso insistir no parentesco entre o institucionalismo da escolha racional e a nova economia institucional, já que é bem sabido que o institucionalismo da escolha racional não passa da extensão da nova economia institucional à Ciência Política (Hall, Taylor, 1996, p. 11; DiMaggio, Powell, 1997, p. 118). Basta lembrar as três correntes, com objetos correspondentes, que fazem parte da Nova Economia Institucional: uma preocupada com as formas de organização, especificamente a firma (Coase, Williamson), outra com a história econômica e a mudança institucional (North, Matthews) e a última com as "situações de equilíbrio no contexto de interações estratégicas" (teoria dos jogos, Schelling, Schotter, Shubik) (Villeval, 1995, pp. 479-480). Essas correntes podem desenvolver-se de maneiras diferentes, mas compartilham do mesmo a priori em relação às instituições, de cálculo otimizador, assumindo uma posição instrumental-funcionalista e contratualista: "as instituições aparecem como modalidades eficazes de coordenação de atores que suprem ou compensam os mecanismos do mercado. (...) Por sua vez, sua gênese é interpretada como o resultado de uma congruência entre decisões individuais, o resultado agregado do cálculo custos/benefícios, o produto de um contrato entre os agentes" (Dutraive, 1995, p. 7).

Quanto à economia das convenções ( economia das convenções), na qual convenção corresponde a instituição, ela pode ser classificada no segundo pólo (institucionalismo sociológico), na medida em que, em parte, reivindica explicitamente um "individualismo metodológico expandido" e uma preocupação com problemas de coordenação (Orléans, 1994, pp. 13-15). Apesar de seu individualismo metodológico, também manifesta interesse privilegiado pela "dimensão cognitiva das regras", entendidas como "dispositivos cognitivos coletivos". Critica igualmente, com Herbert Simon, a nova economia institucional por ignorar "os mecanismos organizacionais chaves como a autoridade, a identificação com a organização e as regras de coordenação". Assim, a economia das convenções adota uma concepção crítica sobre as representações mais comuns do mercado e recusa a idéia, segundo a qual, "as instituições existem apenas referidas a questões de eficiência"; não aceita também a hipótese "da homogeneidade do mundo descrito pela teoria da referência", considerando que se faz face a um "um mundo complexo não homogêneo" (Ughetto, 1999, p. 156). Enfim, a economia das convenções estabelece-se "explicitamente com base na recusa das soluções propostas pelas teoria dos jogos e a economia de informação, em particular, as re- 
ferentes às dificuldades de coordenação. Ao invés do contrato e da hiperracionalidade, que essas posturas sugerem, prefere a noção de convenção, objeto coletivo exterior aos agentes, que serve como uma compensação para a coordenação. Se formos equivaler convenções a instituições, (...) as instituições passam a designar (...) os objetos que escapam à dimensão contratual e que impõem constrangimentos".

A economia das convenções se diferencia da nova economia institucional em economia, da mesma maneira que o neo-institucionalismo sociológico distingue-se do institucionalismo da escolha racional em Ciência Política. Mesmo que os dois tenham o individualismo metodológico como referência e adotem, como o institucionalismo da escolha racional e a nova economia institucional, um enfoque de problem-solving aplicado aos problemas de coordenação dos comportamentos individuais, interessam-se principalmente pelas regras organizacionais, que são consideradas como recursos cognitivos dos atores. Com base nelas, apesar de recusarem o funcionalismo, o instrumentalismo e o intencionalismo da nova economia institucional e do institucionalismo da escolha racional, também consideram que a ação dos atores refletiria basicamente o contexto em que se encontram. Por sua vez, a economia das convenções e o institucionalismo sociológico têm a mesma genealogia e inspiração nos trabalhos sobre a racionalidade limitada, situacional e procedimental de Herbert Simon e James March, que foram os principais introdutores da "ciência cognitiva como tal (...) na teoria da organização" (DiMaggio, Powell, 1997, p. 136)6. Da mesma maneira do que ocorre com o institucionalismo sociológico, "não seria possível propor a economia das convenções como programa de pesquisa sem que tivesse ocorrido antes a viragem 'cognitiva' e 'interpretativa' em ciências sociais" (Favereau, 1995, p. 513). Enfim, a economia das convenções e o institucionalismo sociológico distanciam-se do pólo institucionalista histórico ao abstraírem o conflito entre atores e as relações de poder político, e, consequentemente, ao ignorarem "história da gênese e da formação" das instituições e convenções (Coriat, 1994, p. 151).

Isso se evidencia quando se examina as relações entre a economia

6 Veremos que a noção de justificativa da ação de Luc Boltanski e Laurent Thévenot está muito próxima daquela de legitimação da ação a partir de "cálculos feitos retrospectivamente e de sinais simbólicos" (DiMaggio, Powell, 1997, p. 147) "com o objetivo de dar sentido a seu comportamento" (ibid., p. 139) que se encontra na teoria das organizações.

${ }^{7} \mathrm{Na}$ teoria da regulação, "a análise da dinâmica econômica baseia-se na teorização das formas institucionais, entendidas como expressando a codificação de relações sociais fundamentais. Essas formas tendem a interpretar a reprodução e as transformações de um sistema 
das convenções e a teoria da regulação, que deve ser entendida como a expressão do institucionalismo histórico em Economia: a teoria da regulação opõe às convenções de coordenação os compromissos institucionais reguladores dos conflitos e a expressão estabilizada das relações de poder ${ }^{7}$. As formas institucionais equivalem para a teoria da regulação aos compromissos institucionais que regulam os conflitos mas não fazem com que eles desapareçam, a teoria da regulação concordando com Pierre Bourdieu, de acordo com o qual, toda estrutura implica num certo número de conflitos que dão origem a uma dinâmica endógena à estrutura, "a luta permanente no interior do campo" desempenhando o papel de motor dinâmico dele (Boyer, 1995, p. 25).

De maneira mais ampla, os traços que distinguem o institucionalismo histórico dos outros neo-institucionalismos em Ciência Política podem, em Economia, por isomorfismo, servir para situar a teoria da regulação em relação à nova economia institucional e à economia das convenções. Com efeito, a teoria da regulação, como o institucionalismo histórico, não aborda apenas as instituições a partir dos conflitos entre grupos sociais e a assimetrias de poder; também privilegia, como acabamos de ver, as instituições formais, os macro-objetos, a contingência histórica, uma multi-causalidade contextual, e dá igualmente atenção às consequências não esperadas de práticas sociais individuais e coletivas ${ }^{8}$. Enfim, no que diz respeito às relações entre instituições e comportamentos, a teoria da regulação tem a mesma posição eclética que o institucionalismo histórico: adota simultaneamente um enfoque para a cultura e outro para o cálculo. Esse parentesco próximo não tem mesmo nada de surpreendente, já nos conduz a uma genealogia comum, no caso, uma genealogia estruturalista. A teoria da regulação tem suas origens no estruturalismo marxista, do qual ela recusa todo o antihistoricismo ${ }^{9}$, assim como o institucionalismo histórico em Ciência Política é o herdeiro do estruturalismofuncionalista de Parsons, do qual limpa de todo funcionalismo ${ }^{10}$.

construído com base em relações sociais antagônicas, num processo de organização dos compromissos" (Villeval, 1995, p. 481). "É possível não concluir que há oposição entre os mecanismos de formação das regras (...)? De um lado, armistícios provisórios na luta de classes, de outro, acordo parcial de cooperação entre agentes com racionalidade limitada" (Favereau, 1995, p. 516).

8 Cf. (Boyer, Saillard, 1995), comparar com (Immergut, 1996, pp. 21-23).

${ }^{9}$ A filiação da teoria da regulação é, de fato, ao estruturalismo morfogenético, que Pierre Bourdieu também reivindica em Sociologia: "Não existe antinomia entre estrutura e história e aquilo que define a estrutura do campo (...) é também o princípio de sua dinâmica" (Bourdieu, 1980, Questions de Sociologie, Paris, Minuit, p. 200, citado por Boyer, 1995 a, p. 25). Cf. igualmente (Lordon, 1999, pp. 184-185).

${ }^{10}$ Cf. (Hall, Taylor, pp. 5-6). 
De um outro ângulo, a teoria da regulação e a economia das convenções têm pontos em comum em relação à nova economia institucional. O primeiro "é que não consideram que o mercado seja auto-regulado: num meio incerto, apenas a presença de formas de coordenação não mercantis garante um pouco de regularidade e estabilidade na realização de trocas. (...) Nessa primeira aproximação, tudo se passa como houvesse identidade entre o objeto e as preocupações de convencionalistas e regulacionistas: a atenção às instituições é o que permite compreender porque um mercado fundamentalmente não autoregulado e míope é, mesmo assim, capaz de produzir períodos mais ou menos prolongados de crescimento estável" (Coriat, 1994, p. 143). Portanto, ao passo que a nova economia institucional "estipula que os indivíduos seguem inicialmente seu interesse (o que possivelmente implica em seguir regras), a economia das convenções e a teoria da regulação estabelecem que os indivíduos começam por agir de acordo com regras (o que não impede que realizem, por meio delas, seu interesse)" (Favereau, 1995, p. 514-15). Dito isso, a teoria da regulação e a economia das convenções rejeitam a explicação das formas institucionais dadas pela nova economia institucional por diferentes motivos: a teoria da regulação em razão dela "exagerar a importância da racionalidade individual e mascarar as relações sociais", a economia das convenções "motivada pela atribuição de recursos cognitivos aos agentes econômicos ser irrealista, (ao passo que) as propriedades e os mecanismos das formas institucionais estão profundamente relacionados com os limites da racionalidade individual". Assim, "a teoria da regulação chega às regras pela macroeconomia e a economia das convenções pela microeconomia".

Um outro elemento a aproximá-las é "a permanente abertura em relação às outras ciências sociais, postura que não faz sentido para a economia dominante". Mas na atitude pluridisciplinar, a teoria da regulação dá mais atenção à História e à Ciência Política, ao passo que a economia das convenções procura privilegiar os fundamentos sociológicos.

Em resumo, a teoria da regulação e a economia das convenções adotam estratégias variadas de diferenciação em relação à nova economia institucional, a primeira procurando romper com o individualismo metodológico, enquanto que a segunda continua a se situar dentro dessa referência, ao mesmo tempo que procura alargá-la e enriquecê-la. Em outras palavras, a proximidade do programa de pesquisa não impede que "a maneira como ele é levado a cabo (na teoria da regulação) utilize ferramentas e métodos de investigação claramente distintos, que (...) são tanto indicativos de uma visão diferente sobre a gênese das instituições, quanto de seu modus operandi" 
(Coriat, 1994, p. 143). De fato, a economia das convenções, apesar de tudo, tem certa afinidade eletiva com a teoria econômica neo-institucionalista moderna (Matthews, 1986; North, 1990), com a qual partilha a preocupação de manter uma perspectiva individualista metodológica, ao passo que a teoria da regulação, partindo do pólo oposto, tem uma filiação direta com a escola institucionalista norte-americana de T. Veblen e J. Commons, com a qual a nova economia institucional rompeu, ${ }^{11}$ mesmo que tenha se apropriado de diversos de seus conceitos básicos (Baslé, 1995; Villeval, 1995).

\section{Os novos institucionalismos em Sociologia}

Discutiremos agora a Sociologia institucionalista, se bem que do ponto de vista de Durkheim e Mauss, segundo os quais, a Sociologia é a ciência das instituições, a expressão é um verdadeiro pleonasmo. ${ }^{12}$ Já encontramos em Ciência Política o pólo cognitivo da teoria das organizações, que juntamente com Hall e Taylor (1996), demos o nome de "institucionalismo sociológico". Do ponto de vista da Sociologia, esse institucionalismo sociológico "interpretativo" ou "cognitivo" é o resultado de uma " "revolta microsociológica' ou 'construtivista' que põe fim, durante os anos 60, à hegemonia funcionalista", provocando "um choque de paradigmas na Sociologia norte-americana" (Wacquant, Calhoun, 1989, p. 41). Segundo Loic Wacquant e Craig Calhoun, "essa mudança do centro de gravidade do campo sociológico em direção a um pólo subjetivista" está na origem "da maior presença, ou recuperação, de duas (outras) correntes influentes no campo sociológico norte-americano: a teoria da 'ação racional' (institucionalismo da escolha racional) e a Sociologia histórica e cultural, que são duas posturas epistemológicas e de concepções de ação e da ciência social que se enfrentam". ${ }^{13}$ Reencontra-se também em Sociologia os três pólos, o institucionalismo sociológico, o institucionalismo da escolha racional e o institucionalismo histórico, esse último assumindo a forma de Sociologia histórica e cultural (comparativa).

11 A antiga economia institucional, com efeito, "se diferencia dos enfoques econômicos contemporâneos (...) na medida que suas análises apoiam-se no caráter cultural e coletivos das instituiçõe, o que é incompatível com o individualismo metodológico característico da Nova Economia Institucional" (Dutrive, 1995, p. 9).

12 "O que é uma instituição senão um conjunto de atos ou idéias instituídas que os indivíduos encontram pela frente e que de uma maneira ou de outra são impostas a eles? Não há nenhuma razão, como normalmente se faz, para restringir essa expressão aos arranjos sociais fundamentais. Entendemos, assim, por instituição tanto os usos como os costumes, os preconceitos como as superstições, as constituições políticas como os organismos jurídicos essenciais; já que todos esses fenômenos têm a mesma natureza e apenas diferem em grau. A instituição é, em suma, na ordem social o que a função é na ordem biológica: e assim como a ciência da vida 
"A corrente do institucionalismo da escolha racional não é hoje em dia suficientemente ampla ou homogênea para contar com uma acolhida teórica significativa entre sociólogos". ${ }^{14}$. Mesmo assim, por razões institucionais que não vale a pena estender-se aqui ${ }^{15}$, sua influência social ultra-

é a ciência das funções vitais, a ciência da sociedade é a ciência das instituições assim definidas. (...) As verdadeiras instituições vivem, ou seja, mudam sem parar: as regras da ação não são entendidas nem aplicadas da mesma maneira em diferentes momentos, apesar que as fórmulas que a exprimem permanecerem literalmente iguais. São, portanto, as instituições vivas, tal como se formam, funcionam e se transformam em diferentes momentos, que constituem os fenômenos propriamente sociais, objeto da sociologia" (Fauconnet, Mauss, 1969 (1901), p. 150-151). Essa definição é retomada por E. Durkheim, que insiste em distinguir "os hábitos individuais ou hereditários" que "dominam-nos do interior", ao "nos imporem crenças ou práticas" e "as crenças e práticas sociais (que) atuam sobre nós a partir do exterior", de tal maneira que "a influência exercida por umas e por outras é (...), no fundo, muito diferente" (Durkheim, 1969 (1901), p. xxi-xxii): “(...)as maneiras coletivas de agir ou de pensar têm uma realidade exterior aos indivíduos que, em cada momento, a ela se conformam. São coisas dotadas de existência própria. O indivíduo as encontra completamente formadas e não pode impedir que existam ou que existam de modo diferente (...). O indivíduo desempenha sem dúvida um papel na sua gênese. Mas, para que haja fato social, é necessário que vários indivíduos tenham, pelo menos, combinado a sua ação e que desta combinação tenha resultado um produto novo. Ora, como esta síntese se processa fora de cada um de nós (uma vez que há pluralidade de consciências), ela tem também necessariamente por efeito fixar, instituir fora de nós certas maneiras de agir e certos juízos que não dependem de cada vontade particular. Tal como fizemos notar, (...) há uma palavra que, desde que se lhe dilate um pouco a acepção vulgar, exprime bastante bem esta maneira de ser muito especial: é a palavra instituição. Pode-se, com efeito, sem desvirtuar o sentido deste termo, chamar instituição a todas as crenças e a todos os modos de conduta instituídos pela coletividade; a Sociologia pode então ser definida como a ciência das instituições, da sua gênese e do seu funcionamento (ibid., p. xxii; citado em parte em Gislain, Steiner, 1995, p. 83).

13 Para Wacquant e Calhoun, trata-se de um "confronto de paradigmas provenientes de dois pólos epistemológicos cujas força de atração são atualmente crescentes no campo das ciências sociais norte-americanas e que podemos, de maneira apressada e simplificada, caracterizar como: de um lado, o pólo individualista e racionalista, que entende a ordem social como a agregação, simples ou composta, de ações individuais realizadas por agentes que procuram deliberadamente maximizar sua utilidade pelo ajuste instrumental de meios disponíveis a fins claramente dados e ordenados; do outro lado, encontra-se o pólo histórico e culturalista, que se esforça em compreender a lógica dessas mesmas ações tomando seu significado subjetivo e contextual, e procura descobrir a lógica de constituição dos agentes e de seus fins, retraçando suas influências recíprocas no tempo" (Wacquant, Calhoun, 1989, p. 52).

14 Não deixaria de surpreender que fosse diferente, visto o paradoxo que está por trás da idéia de se fazer uma sociologia que nega a especificidade da Sociologia. A institucionalismo da escolha racional, com efeito, "supõe resolver a questão da natureza e da lógica imanente das condutas sociais, o que impede de colocar como problema aquilo do qual ela não trata (...) o objeto" da Sociologia (Wacquant, Calhoun, 1989, p. 47). Em outras palavras, omitindo a questão das condições sociais na formação dos interesses, das preferências e dos fins dos atores, o institucionalismo da escolha racional "se fecha a possibilidade de ver o indivíduo como uma construção social e histórica, também passível de uma análise sociológica" (ibid., p. 51).

15 Cf. sobre esse ponto Wacquant, Calhoun, 1989, pp. $42-43$ e p. 45. 
passa em muito a influência intelectual, com o institucionalismo da escolha racional representando atualmente "uma importante força na Sociologia norte-americana ortodoxa ${ }^{16}$. James Coleman, autor relevante devido a amplitude de sua obra, foi o principal introdutor nos EUA, durante os anos 1980, do institucionalismo da escolha racional em Sociologia (assim como Raymond Boudon o foi na França). A especificidade do institucionalismo da escolha racional sociológica é focalizar a passagem do micro para o macro, procurando introduzir, de diferentes formas, "a noção ausente de estrutura social" no modelo econômico. "O mérito de Coleman está em ir além das hipóteses exageradamente simplificadoras, por exemplo, de um Becker, ao reconhecer a existência de mecanismos de 'tradução' do micro para o macro que vão além do mercado". Assim, para Coleman, a passagem do micro ao macro se dá por meio de três grandes mecanismos: os mercados, as hierarquias e os sistemas normativos ${ }^{17}$. Mas, de acordo com ele, "pode-se dizer que se explicou uma instituição ou um processo social se e somente se se deu atenção à ação racional dos indivíduos", "o sociólogo de Chicago indo ao ponto de explicar as normas como o resultado da ação racional de agentes racionais que procuram regular eficazmente as condutas de terceiros, que sentiram os 'efeitos secundários negativos". Em poucas palavras, retomando as categorias de Olivier Favereau, é possível considerar que a sociologia de Coleman tem a mesma postura para a "teoria convencional estendida" em Economia, isto é, a nova economia institucional, que a "sociologia" beckeriana tem para a "teoria convencional".

Mas "se Coleman e o institucionalismo da escolha racional representam uma das mais influentes correntes da Sociologia norte-americana ortodoxa (...), Skocpol e os macro-sociológos estruturais representam outra vertente, também muito influente, mesmo que mais dispersa”. Eles estão muito próximos do institucionalismo histórico prevalecente em Ciência Política, com o qual compartilham a maior parte dos princípios metodológicos: focalizam macro-objetos; levam em conta a contingência

16 Essa influência do institucionalismo da escolha racional transparece no "marxismo analítico", que nos trabalhos de J. Elster, C. Offe, E. Olin Wright, A Przeworski e J. Roemer, ambiciona "retomar os problemas do marxismo apoiado na metodologia neoclássica", fazendo assim "da estrutura de relações sociais o produto da agregação composta e não intencional de escolhas deliberadas de indivíduos que maximizam seu interesse ao longo da interação de estratégias limitadas pela distribuição de recursos eficientes" (ibid., p. 44).

17 Por vezes ele acrescenta, como mecanismo, as regras de escolha social - os sistemas eleitorais, por exemplo - e os comportamentos coletivos, como pânicos e rumores. 
histórica e a variedade cultural dos contextos estruturais e, assim, as visões de mundo dos atores; reconhecem a existência de racionalidades alternativas; fazem uso de uma multicausalidade contextual; reconhecem a importância para a mudança estrutural do cálculo empregado por atores em conflito, mas com base em interesses interpretados e construídos histórica e socialmente; consideram que grande parte dos resultados intencionais de estratégias sociais são desenvolvidos com base em efeitos sistêmicos. Por outro lado, essa sociologia histórica comparativa "estrutural" representa também uma tendência mais "culturalista". Essa convivência se encontra igualmente no institucionalismo histórico em Ciência Política (Immergut, 1996, p. 24). Dessa forma, é possível considerar que o institucionalismo histórico assume, nos EUA e na sociologia mais influenciada pelos anglo-saxões, a forma da sociologia histórica comparativa. Consequentemente, a Sociologia é também estruturada em três grandes pólos institucionalistas, similares àqueles que prevalecem em Ciência Política e Economia..

Mas essa divisão tripartide da sociologia institucionalista aparece na França? Isso é menos claro, já que os enfoques encontram-se mais dispersos, mas, mesmo assim, existem numerosos indícios que a resposta é positiva. Antes de mais nada, como já foi sugerido, o institucionalismo da escolha racional de Coleman assume a forma do "individualismo metodológico 'revisitado' à maneira de Raymond Boudon” (Maurice, 1994, p. 647) ${ }^{18}$. Quanto ao institucionalismo sociológico da teoria das organizações, ele corresponde, em grande parte, à "sociologia (convencionalista) de regimes da ação iniciada por Luc Boltanski e Laurent Thévenot" (Corcuff, 1999, p. 97), mas, sem dúvida, seria também possível relacioná-lo com uma parcela da nova sociologia econômica, em especial, àquela que privilegia a análise dos meios sociais (Granoveter, 1994) ${ }^{19}$. Enfim, certas características do institucionalismo sociológico aparecem numa grande variedade de formas de sociologia histórica e cultural, do estruturalismo genético da sociologia de Bourdieu, que, como vimos, inspira a teoria da regulação em Economia, à teoria da regulação combinada de J.-D. Reynaud (Reynaud, 1989), passando pelo enfoque do efeito societal, que também é bastante próximo da teoria da regulação (Théret, 1997 e 2000).

$18 \mathrm{O}$ parentesco entre os trabalhos de J. Coleman e R. Boudon é evidente e foi sublinhado por Wacquant e Calhoun.

19 Cf. (Steiner, 1999) para uma apresentação das diversas correntes dessa sociologia. 
Não poderemos, entretanto, realizar uma análise mais aprofundada do que aproxima e distancia essas diversas sociologias, principalmente as classificadas no mesmo pólo, como fez Immergut (1996) em relação aos diversos institucionalismos desenvolvidos em Ciência Política. Isso nos afastaria de nosso objetivo, que é mostrar o que aproxima diversas correntes representativas de um mesmo grande paradigma, válido para além das fronteiras disciplinares, assim como as eventuais tendências de convergência intelectual desses macro-paradigmas, que é o segundo ponto sobre o qual trataremos agora.

\section{EM DIREÇÃO A UMA SÍNTESE INSTITUCIONALISTA?}

As instituições que, na origem, teriam sido “'divisora de águas', teriam convertido-se num espaço de confluência?" (Vileval, 1995, p. 479). À luz de desenvolvimentos recentes nos três grandes pólos do novo institucionalismo, impulsionados por suas insuficiências teóricas iniciais, é possível pensar dessa maneira, mas é preciso fazer a ressalva que essa é uma simples tendência, sempre problemática e que não levará ao desaparecimento da diversidade de paradigmas.

\section{Sobre as convergências intradisciplinares}

Essa tendência foi destacada em Ciência Política por Hall e Taylor. Segundo eles, o pivô da evolução convergente dos três institucionalismos foi o institucionalismo histórico, na medida em que "muitos de seus argumentos recentes poderiam ser imediatamente traduzidos para a perspectiva da escolha racional, ao mesmo tempo que autores identificados com a tradição também mostraram-se abertos para argumentos do neo-institucionalismo em Sociologia. As melhores análises do institucionalismo histórico já indicavam uma espécie de integração de paradigmas, sugerindo, por exemplo, como atores históricos selecionam instituições em razão de fins instrumentais, de maneira similar, portanto, ao que a escolha racional prevê, mas, ao mesmo tempo, encaravam a seleção dessas instituições a partir de mecanismos do institucionalismo sociológico, ou seja, como um menu de alternativas que se tornam historicamente disponíveis" (Hall, Taylor, 1996, p. 24).

Por outro lado, alguns politicólogos identificados com o institucionalismo da escolha racional, como Barry Weingast, começaram a levar em conta o papel das idéias e das visões de mundo nos seus modelos de jogos 
e jogadores, agora envolvidos com contextos culturais específicos. Segundo esses autores, "o argumento de Thomas Schelling relativo aos 'pontos focais' sugere que fatores tais como a cultura, a história, as idéias e as instituições tudo aquilo que pode fornecer as bases para um sistema de crenças compartilhadas - desempenham um importante papel. (...) Em poucas palavras, algumas soluções são mais prováveis porque os atores crêem que os outros também as escolherão" (Garret e Weingast, 1993, p. 182)20

Enfim, no caso do institucionalismo sociológico, apesar de todo o interesse que foi demonstrado pela viragem cognitiva na atividade e razão prática, "qualquer coisa se perdeu na passagem do antigo para o novo institucionalismo", na medida em que esse último "deu, até o momento, atenção sobretudo aos processos de legitimação e de reprodução institucional. (...) Ora, as instituições não são constrangimentos para a ação: elas são antes e acima de tudo produtos da atividade humana" (DiMaggio e Powell, 1997, p. 147). Um número considerável de partidários do institucionalismo sociológico tendem, consequentemente, a reconhecer que os "processos nos e pelos quais se constróem as regras são essencialmente conflitivos e competitivos, como provam a maior parte das lutas políticas nas sociedades modernas, que se dão em torno da formação e da revisão dos sistemas de regras que orientam a ação política e econômica. Daí a idéia de que se as regras e as rotinas produzem ordem e minimizam a incerteza, a criação e a ativação de dispositivos institucionais seriam igualmente inseparáveis do conflito, da contradição e da ambiguidade". Em poucas palavras, as premissas do institucionalismo sociológico "esforçam-se ultimamente em ampliar o enfoque, incorporando a contribuição de pesquisadores que enfatizam os elementos políticos e estratégicos da ação e da mudança institucional, procurando articular, de maneira mais sólida, o institucionalismo organizacional e a Sociologia em geral, introduzindo, dessa forma, na agenda científica o papel dos interesses e do poder, e clarificando e aprofundando o que deveria ser uma teoria da mudança institucional".

Para Hall e Taylor, é defensável que uma tal abertura dos enfoques se acentue ${ }^{21}$. Até porque, aos olhos de insitucionalistas históricos, sua escola "pode beneficiar-se de trocas mais intensas", em razão de seu ecletismo

20 Também "no nosso modelo, as idéias são importantes em razão delas desempenharem papel na coordenação de expectativas que são necessárias para basear a cooperação entre um conjunto de jogadores que possuem preferências divergentes" (ibid., p. 205).

21 "Chegou a hora de ocorrerem grandes trocas entre elas. No mínimo, um melhor conhecimento mútuo levará os partidários de cada uma a uma apreciação mais sofisticada dos problemas ainda a serem resolvidos no interior de cada paradigma" (Hall e Taylor, 1996, p. 22). 
(lembremos que "é comum para as análises dessa tradição utilizarem por vezes o enfoque do cálculo e da cultura) não ter dado "a devida atenção ao desenvolvimento de uma interpretação sofisticada e mais precisa de como as instituições afetam o comportamento" (Hall, Taylor, 1996, p. 17). Quanto ao institucionalismo sociológico, consciente que está que atribui "pouca atenção às lutas pelo poder nos processos de criação e reforma das instituições", também só poderia ganhar "ao dar mais atenção aos planos de significação, os roteiros e os símbolos aparecendo não somente como processos de interpretação, mas também como elementos constitutivos da disputa e da contestação. Por fim, se a teoria da escolha racional não quiser ser aplicada apenas "a um número reduzido de conjuntos institucionais"22, deve igualmente estar pronta para alargar suas hipóteses e dar mais espaço às dimensões herdadas e aos aspectos cognitivos das instituições, seguindo o exemplo do que Douglas North (1990) começou a fazer em Economia.

De fato, se prestarmos atenção à Economia, podemos observar um processo desse tipo. Na França isso se deu mediante a um diálogo explícito entre a teoria da regulação e a economia das convenções, que conduziu a trabalhos realizados conjuntamente e que utilizaram igualmente o institucionalismo da escolha racional (teoria dos jogos) na análise de alguns problemas particulares ${ }^{23}$. Como o institucionalismo histórico em Ciência Política e a sociologia histórica comparativa em Sociologia, a teoria da regulação, por prestar atenção sobretudo a macro-objetos, tendeu a não aprofundar a análise da relação entre instituições e comportamentos individuais, o que se pode exprimir afirmando que, em Economia, a teoria da regulação não possui uma microeconomia correspondente à sua macroeconomia. A superação dessa ausência é reconhecida pelos regulacionistas como um objetivo prioritário: "na atual evolução da teoria da regulação o encontro com a microeconomia e o confronto com certos enfoques heterodoxos - inclusive individualistas - é um caminho necessário e frutífero"

22 Os postulados do institucionalismo da escolha racional "fazem com que o plano de ação racional seja particularmente aplicável aos contextos sociais em que os agentes estão significativamente individualizados e claramente definidos culturalmente, chegando facilmente a acordos sobre seus interesses e onde a comparação sobre alternativas é imediata, com a informação sendo barata, completa e suscetível de ser submetida a critérios de decisão unívocos. (...) A situação que melhor corresponde à institucionalismo da escolha racional é a do consumidor fazendo suas compras num supermercado. O problema é saber se é aceitável generalizar o paradigma da compra numa 'concepção da sociedade como lanchonete' (...) ou como uma enorme partida de Banco Imobiliário" (Wacquant, Calhou, 1989, p. 52).

${ }^{23}$ Cf. (Villeval, 1995, p. 484); (Chartres, 1995). 
(Coriat, 1994, p. 152)24. Daí a conclusão que é possível se aproximar da economia das convenções, devido a posições convergentes em relação à nova economia institucional e ao entendimento das instituições como mediações entre o individual e o coletivo. Além de tudo, a economia das convenções ressente-se da falta de uma macroeconomia correspondente à sua microeconomia. (Aglietta, 1997, p. 423). De acordo com Robert Boyer, essas "aproximações com a economia das convenções (...) representam o início de uma teoria das formas de organização, convenções e instituições" (Boyer, 1995b, p. 534). Bernard Billaudot, por seu turno, vai ao ponto de considerar que a renovação da teoria da regulação deve seguir um caminho que "combine programas de pesquisa regulacionistas e covencionais" (Billaudto, 1996, p. 141). Uma convergência poderia, assim, se produzir entre uma teoria da regulação purificada de sua origem marxista "e centrada nas propriedades dinâmicas das formas institucionais" e uma economia das convenções "orientada para a dinâmica de aprendizado relacionada a um conjunto institucional dado" (Favereau, 1995, p. 514).

Convém acrescentar que desenvolvimentos no campo neoclássico "modificaram radicalmente as relações entre os enfoques dominantes no seu interior e o regulacionismo. O motivo para isso é que as correntes de análise neoclássicas mais inovadoras e fecundas reconhecem - de maneira que está longe de ser única - que as instituições devem ter um lugar central no desenvolvimento das lógicas econômicas. Isto que descarta a idéia - fundadora nos enfoques neoclássicos anteriores - de que as instituições estabelecem, no final das contas, formas de rigidez que criam obstáculos para o pleno desenvolvimento de mercados em equilíbrio. Essas conclusões são o resultado de uma década de pesquisas intensas e fecundas para enfrentar paradoxos e desafios à capacidade de previsão da teoria. A teoria neoclássica acabou, assim, por “descobrir' o papel das instituições na Economia, em relação paralela com desenvolvimentos similares na teoria da organização, surgindo dessas descobertas uma 'ortodoxia' significativamente renovada" (Coriat, 1994, pp. 135-136). É por isso que North, nos seus trabalhos mais recentes, questiona diversos postulados fundamentais do institucionalismo da escolha racional, em parte endogenizando as preferências (Coban, 1995, p. 499), o que faz com que considere que as instituições não apenas constrangem as escolhas como também modelam o comportamento, além de reavaliar o papel da eficácia na seleção de insti- 
tuições (Chartres, 1995, p. 274) e colocar em perspectiva o papel da coerência macrosocial das instituições no processo de seleção (Villeval, 1995, p. 485). Por fim, insiste no papel das idéias, das ideologias e dos dogmas nos processos de escolha individual (North, 1990, p. 22) ${ }^{25}$. Essa tendência de aproximação de pontos de vista variados também pode ser notada nos economistas radicais norte-americanos fundadores do enfoque da estrutura social da acumulação, quando reaproveitam algumas hipóteses e métodos da nova economia institucional (Coban, 1995).

Por fim, o que está acontecendo em Sociologia? Aparentemente, pelo menos no final dos anos 1980, segundo Wacquant e Calhoun (1989), não houve aproximação, mas, ao contrário, distanciamento do institucionalismo da escolha racional e da sociologia histórica comparativa. É evidente, porém, que o institucionalismo da escolha racional sociológica, apesar de suas declarações de intenção, faz uso de um individualismo metodológico muito mais mitigado do que o do da nova economia institucional ou da public choice, eventualmente fazendo uso do culturalismo e mesmo do holismo. Pode-se tomar o caso de Raymond Boudon como exemplo. Com efeito, mesmo que explique um fenômeno social pelo comportamento dos indivíduos, esses são tomados como portadores de informações globais macroscópicos que, somando tudo, são o que explica o fenômeno em questão (Boudon, 1994, p. 47). Dessa maneira, "a agregação de comportamentos individuais", visando explicar fenômenos sociais, converte-se numa simples "função" desses comportamentos, o que faz com que se procure, sem sucesso, a expressão precisa de sua forma. Sobre isso, Boudon menciona apenas "o efeito de agregação resultante da combinação de uma multiplicidade de comportamentos individuais racionais" e o "resultado dos comportamentos microscópicos".

Assim, para Boudon, os comportamentos individuais apenas participam da mediação entre as variáveis macro-contextuais e os fenômenos sociais estudados. Não é precisado, entretanto, a forma que essa mediação assume, mas ela não é assimilável à agregação aritmética de comportamentos individuais homogêneos. Enfim, a racionalidade de comportamentos individuais, a qual Boudon faz referência, está longe da racionalidade maximizadora dos economistas, aproximando-se mais de uma racionali-

25 Daí uma avaliação que se aproxima da de Hall e Taylor: "As hipóteses de comportamento utilizadas pelos economistas são úteis para resolver certos problemas. Para muitos problemas enfrentados pelos pesquisadores de ciência social elas são, entretanto, inadequadas, impedindo a compreenção da existência, formação e evolução das instituições" (ibid., p. 24). 
dade de tipo weberiana, adaptativa, situacional, contextual e que simplesmente indica que todas as estratégias são "compreensíveis se relacionadas com a situação dos atores". É reconhecida aí a existência de uma multiplicidade de racionalidades. Também admite-se os limites do individualismo metodológico em Sociologia, limites esses que estariam relacionados à complexidade das sociedades e explicariam porque "a forma de pensar holista é amplamente dominante nas ciências sociais". Boudon se limita, finalmente, a insistir que se tenha uma melhor compreensão do papel dos atores individuais e coletivos nos processos sociais, evitando que eles sejam considerados como "marionetes cujos fios seriam manipulados pelas estruturas". Em poucas palavras, o individualismo metodológico de Boudon, apesar das suas declarações de intenção, que dão espaço para interpretações equivocadas, ${ }^{26}$ tem pouco a ver, até por ser Sociologia, com o do institucionalismo da escolha racional e da teoria econômica padrão.

Por outro lado, vimos como, na Ciência Política, o neo-institucionalismo da teoria das organizações aproximou-se da Sociologia histórica, ao procurar dar atenção aos conflitos de interesse e ao impacto sobre os comportamentos de macro-instituições ou instituições formais. Na mesma direção, os debates no interior da sociologia histórica comparativa entre estruturalistas e culturalistas levaram a um melhor uso de idéias e dispositivos cognitivos coletivos por parte dos primeiros. Dessa forma, Theda Skocpol, originalmente uma eminente "representante da análise estrutural pura e dura", reconhece ter subestimando o papel das ideologias em seus primeiros trabalhos. Propõe, a partir daí, "uma concepção que enfatize o papel da ação", na qual distingue "a ideologia" propriamente dita, que define como "sistema de idéias utilizados por atores políticos identificáveis com argumentos políticos explícitos" e os "idiomas culturais", dotados "de uma existência na longa duração, mais anônimos e menos engajados" e, "a partir dos quais, os agentes podem mesmo fabricar as ideologias, num trabalho simbólico e organizacional próprio" (Wacquant, Calhoun, 1989, p. 50).

No que se refere à França, observa-se também na Sociologia inspirada em Bourdieu, o desenvolvimento de um programa de pesquisa que visa dar mais atenção às condutas individuais dos agentes (Lahire dir., 1999). trata-se de um programa com a ambição de desenvolver uma "sociologia no âmbito do indivíduo" (Lahire, 1999, p. 147). Isto é, uma "sociologia psi-

${ }^{26}$ Esse jogo de palavras evidencia-se particularmente quando Boudon interpreta como "efeito da agregação", "resultado das ações, das atitudes ou comportamentos individuais" a idéia de Simmel, segundo a qual, as "ações recíprocas intercambiadas pelos indivíduos" são o fundamento dos fenômenos sociais. 
cológicoa" do "social individualizado", sociologia essa que presta atenção às "lógicas sociais desenvolvidas no âmbito (do) (...) sujeito empírico (que não lembra em nada o indivíduo desocializado do individualismo metodológico)". Essa sociologia, que busca combinar determinismo social e "indeterminação relativa do comportamento individual", se coloca como tarefa explícita responder à "necessidade histórica de pensar o social numa sociedade fortemente individualista". Tomando como ponto de partida a idéia de que a sociedade apresenta uma pluralidade de esferas de atividade, ela substitui "à coerência e à homogeneidade das disposições individuais, normalmente imaginada por sociólogos em relação a grupos ou instituições, (...) uma visão mais complexa do indivíduo, menos unificado e portador de 'habitus' (planos ou disposições) heterogêneos e, em certos casos, contraditórios". Baseando-se no conceito de "habitus" e na noção de "disposição, que é central para pensar o passado incorporado ao âmbito individual", seu programa de pesquisa considera que é preciso, por um lado, "testar as pesquisas empíricas" afim de "ultrapassar a mera invocação ritual do passado incorporado", e, por outro lado, pergunta-se "como as múltiplas disposições incorporadas, que não formam necessariamente um 'sistema' coerente, organizam-se (...) ou articulam-se" e são capazes de atualizar-se em diversos contextos", ou então, são "inibidas ou desativadas".

Assim, da mesma forma que a teoria da regulação procura a microeconomia correspondente à sua macroeconomia, a sociologia esturalgenética, inspirada em Bourdieu, busca a microsociologia correspondente à sua macrosociologia, isto é, uma apreciação mais fina e complexa da maneira como as instituições influenciam os comportamentos individuais por meio da formação de "habitus" e o conjunto variado de disposições incorporadas. Esse programa de pesquisa a conduz a considerar "o indivíduo como produto complexo de diversos processos de socialização", o que, consequentemente, a aproxima da sociologia dos regimes de ação no estilo Boltanski-Thévenot, e também de preocupações de um certo individualismo metodológico, como o de Boudon.

Do ponto de vista do efeito societal, observa-se igualmente uma volta ao holismo durkheiminiano original e uma abertura aos problemas de coordenação e à problemática cognitiva das convenções (Maurice, 2000, pp. 34-36; Verdier, 2000). Também a teoria da regulação evoluiu, nos anos 1990, para uma postura que passou a dar crescente atenção, junto com os conflitos, a problemas de coordenação interindividual, o que fez com que se aproximasse da economia das convenções e da sociologia das organizações (Reynaud, 1999; Thoenig, 1998). 


\section{Uma concepção "mediana" e sintética da instituição}

Não se trata de deduzir dessa evolução dupla quase geral que os três grandes pólos do novo institucionalismo vão se encontrar numa posição comum. É verdade que ocorre, por um lado, uma articulação do micro e do macro que enfatiza o papel das mediações nesses dois níveis dos fenômenos sociais, e desenvolve-se, por outro lado, a complexificação da relação entre as instituições e a conduta dos atores, o que abre caminho para comportamentos inovadores em planos institucionais dados. Mesmo assim, não trata-se de sugerir que haverá a combinação de uma concepção de gênese das instituições a partir de conflitos de poder, relacionados com problemas de coordenação, com uma percepção que prestaria atenção a comportamentos, por vezes, estratégicos e rotineiros. Trata-se, na verdade, principalmente de estabelecer uma posição "mediana", em torno da qual, se dirigem pelo menos certas correntes de cada grande paradigma, posição que aponta para uma concepção das instituições e sua eficácia social mais rica, mais heurística, do que aquela privilegiada em cada pólo específico dos paradigmas. O importante, no estágio atual da evolução das pesquisas, é que cada paradigma utiliza-se de problemas colocados pelos concorrentes, procurando respondê-los, a partir de sua problemática, já que é apenas a partir de respostas alternativas oferecidas a questões idênticas que os diversos paradigmas podem realmente ser comparados cientificamente.

É, em primeiro lugar, o que se observa na prática, para além das alianças que buscam estabelecer uma divisão do trabalho entre enfoques, mesmo quando elas se baseiam em pressupostos epistemológicos heterogêneos, como no caso da economia das convenções e da teoria da regulação ${ }^{27}$. A partir de alianças como essas é possível criar uma verdadeira convergência, até porque mesmo as escolas não são homogêneas. Assim, por exemplo, a teoria da regulação, na busca de uma viragem interpretativa e cognitiva a fim de estabelecer sua microeconomia, não vai utilizar o "dispositivo cognitivo coletivo" estabelecido pela economia das convenções para resolver problemas de pura coordenação, mas sobretudo o "sistema simbólico" - que associa a dimensão cognitiva com relações de dominação -, numa perspectiva mais de acordo com sua epistemologia

27 Isso foi ressaltado por (Coriat, 1994, pp. 150-152), (Aglietta, 1997, pp. 411-412) e (Lordon, 1999, pp.182-188). 
estruturalista e que implica em não "deixar o cognitivo só para os cognitivistas" (Lordon, 1999, p. 183) 28.

A perspectiva aberta pelas interdependências estruturais entre os diversos pólos dos paradigmas do institucionalismo atual e pelas evoluções dinâmicas desses pólos no sentido de uma certa convergência é, portanto, sobretudo de elaboração de uma concepção sintética nova da instituição, que leva em conta o conjunto dos elementos privilegiados por cada um deles. Isso faz com que se redifina, no plano dos dois critérios que foram utilizados para diferenciar os pólos, uma posição eclética, "mediana”, considerando que a instituição deve combinar o enfoque de cálculo e de cultura, e que ela deve igualmente ser considerada como o resultado de um conflito em que se utilizam tanto a convenção como a cooperação.

No que se refere ao primeiro critério, pode-se generalizar a posição de Hall e Taylor e notar que os novos institucionalistas históricos (institucionalismo histórico, teoria da regulação, sociologia histórica comparativa), que apontam para a necessidade de um enfoque que combine cálculo e cultura, estão, desde já, próximos de uma posição mediana. As instituições realmente favorecem também os comportamentos e as transações estratégicas orientadas para o futuro, ao passo que as disposições rotineiras existem baseadas no passado. Elas são, assim, mediações entre atores e estruturas, que podem desempenhar um duplo papel, dos primeiros em relação às segundas e das segundas em relação aos primeiros.

No que diz respeito ao segundo critério, baseado na oposição entre, por um lado, coordenação e recursos cognitivos e, de outro lado, no con-

28 Da mesma maneira, a preocupação da teoria da regulação em procurar mediações entre comportamentos microeconômicos e grandes regularidades macroeconômicas não a impediu de privilegiar o papel da política no estabelecimento de mediações, colocando a ênfase na eficácia das instituições formais: "a economia das convenções e a teoria da regulação entendem explicitamente as instituições como mediações. As empresas são organizações de coordenação entre micro e macroeconomias (...) As diferenças entre a economia das convenções e a teoria da regulação em relação ao papel das mediações para dar conta das regularidades macroeconômicas referem-se aos pontos de vista sobre a formação das entidades coletivas pelas quais as mediações são realizadas. A economia das convenções tem a tendência de prestar atenção a processos espontâneos que emergem da interação de indivíduos que buscam seus interesses. A teoria da regulação, ao contrário, insiste na capacidade de se estabelecer e buscar interesses coletivos organizados. A ação criativa da instituição é essencialmente política e a política nunca é uma prática individual. Assim, a intervenção de governos, as lutas sociais conduzidas ou exploradas por organizações representativas de grupos, a formalização do compromisso por parte do legislador, devem ser, em parte, consideradas para dar conta da transformação das instituições e para descrever a hierarquia de suas relações (Aglietta, 1997, pp. 424-425). Cf. igualmente sobre esse ponto (Boyer, 1999). 
flito e recursos de poder, deve-se seguir o apelo de DiMaggio e Powell e partir de um reaproveitamento das contribuições da "antiga economia institucional" (DiMaggio e Powell, 1997, p. 114). De fato, encontra-se no antigo institucionalismo econômico, particularmente na obra de John Commons, uma concepção de instituição que corresponde perfeitamente a uma postura eclética sobre esse segundo critério.

Commons define instituição de forma ampla como o resultado de toda transação entre pessoas envolvendo regras operativas que estabilizam a tensão entre as outras duas dimensões das transações, que são o conflito e a cooperação. Para ele, o fato de duas pessoas estranhas estabelecerem transações entre si significa que elas se encontram num estado de interdependência de fato, e, portanto, possuem a obrigação de buscar a coordenação, ao mesmo tempo que há entre elas oposição, a priori, em relação aos resultados da transação; assim, de um lado, elas dependem umas das outras, sendo esse inclusive o motivo da realização da transação, o que não impede, por outro lado, que entrem em conflito sobre a distribuição dos recursos que pensam em conseguir. Se o conflito, que exprime a independência dos protagonistas, supera a cooperação, que sua interdependência exige, a transação não ocorre; o conflito exagerado põe fim a cooperação e, no nível social, as interdependências sociais são negadas. Ao contrário, se a cooperação é excessivamente dominante, o conflito se perde, e à nível social, o perigo é de se abri mão do dinamismo da sociedade, incapaz de evoluir e se adaptar de maneira endógena às modificações de seu ambiente.

A instituição é, dessa perspectiva, o que permite manter, estabelecendo limites, a tensão dinâmica entre os princípios do conflito e da cooperação, que são constitutivos das transações: as regras comuns aceitas pelos agentes nas transações introduzem princípios de ordem que permitem que elas sejam operadas e reproduzidas no tempo. Essa concepção das instituições, como regras de "ação coletiva que controlam, restringem ou libertam a ação individual" (Commons, 1989 (1934), p. 73), permite explicar sua gênese nos desencontros da oposição conflito/cooperação, já que apesar de serem princípios de uma ordem "estabelecida pelo conflito", elas funcionam também como convenções de cooperação e, portanto, como regras de coordenação.

Nessa perspectiva, mais do que constrangimentos coletivos que pesam sobre os comportamentos, as instituições são encaradas como redes cognitivas capazes de estimular a ação individual; ou seja, estruturas de estímulo. Por outro lado, a partir da projeção no futuro, o projeto individual é valorizado ao ponto que ele passa a fazer parte até mesmo da representação 
da pessoa, a incorporação de disposições e a formação de "habitus" não podendo ser vistas como sinônimos da incultação de normas de reprodução correspondentes a posições sociais e condutas individuais ${ }^{29}$. É por isso que as instituições não são necessariamente obstáculos à inovação, mas podem, ao contrário, estimular a mudança, inclusive uma mudança radical.

Uma concepção dinâmica da instituição, tal como a do antigo institucionalismo, que vê a instituição como regulação de conflito, e, portanto, um compromisso, mas simultaneamente como uma convenção para a cooperação, faz dela um possível ponto de convergência para os novos institucionalismos. Passa a estar em jogo, com ela, uma concepção extensiva das instituições, que abarca o amplo espectro de tudo que faz o indivíduo um ser imediatamente social, já que ele chega ao mundo numa sociedade que existia antes e que vai continuar a existir depois dele: o "habitus" e as disposições incorporados, o sistema de valores e normas sociais relevantes na ética - constrangimentos morais, crenças - na cultura histórica - usos e costumes, a moeda, as regras jurídicas, os discursos convencionais, os poderes organizados, privados ou públicos, de coerção econômica, política e simbólica ${ }^{30}$.

Ora, tal concepção, que pode se encontrar em Sociologia ${ }^{31}$, possivelmente cria um problema para o institucionalismo histórico, sobretudo em Ciência Política mas não apenas aí, na medida em que ele interessa-se sobretudo por macro-objetos e instituições formais. É possível, dessa maneira, estabelecer um desacordo, de um lado, entre sociólogos e econo-

29 Seria ainda necessário acrescentar que, levando em conta a pluraridade de disposições incorporadas, toda mudança de contexto que modifica as condições de atuação diferencial, ao reorganizar a estrutura de mobilização de diversos registros de disposição, pode levar a mudança de comportamentos e a ações inovadoras.

30 “A noção de instituição parece complexa e sugere um conjunto de elementos a priori, tão diversos como, num primeiro registro, a família, a Igreja, o Estado; num outro registro, a interdição do incesto ou do crime, a proibição da obrigação de vingança (vendetta); ou ainda, o casamento, os direitos de propriedade, enfim, a prioridade ao direito, ao cheque bancário, ao desemprego, ao Domingo..., diversidade que é preciso realizar um esforço para extrair um princípio comum (...). Uma vez filtrada a polisemia do conceito de instituição, resta a idéia de um conjunto de regras mais ou menos formais, as "regras do jogo" sociais ou de uma comunidade particular, indo dos costumes ao direito ou à constituição de uma nação" (Dutraive, 1995, pp.7-9).

31 Cf. supra nota 11. Por outro lado, "a sociologia durkheiminiana insiste no caráter constrangedor das regras, o que se manifesta nas sanções explícitas que asseguram a conformação das condutas às normas ou, dito de outra maneira, o controle da ação individual (...)”, bem que "os economistas institucionalistas americanos acrescentam a esse constrangimento o caráter permissivo da ação - no sentido do quadro para a ação - e de incitação das instituições, que "liberam e limitam o campo de ação individual" (Dutraive, 1995, p. 9). 
mistas, que se identificam com uma concepção ampla de instituições, que chega a incluir as crenças e as rotinas, e, de outro lado, a postura de historiadores, juristas e cientistas políticos, ${ }^{32}$ que tendem a levar em conta apenas as Instituições (com um I maiúsculo), isto é, as regras do jogo social não incorporadas, "institucionalizadas", codificadas e tornadas públicas.

Mesmo assim, essa oposição não é tanto profunda e real, mas sobretudo superficial. Desde que se considere, como é comum em Sociologia Bourdieu, por exemplo, distingue seguindo Durkheim, dois tipos de "realização do social: nas coisas, pela instituição e nos corpos, pela incorporação" (citado por Boyer, 1995, p. 25) - que há uma diferença significativa entre as instituições informais, incorporadas, inculcadas, interiorizadas na psiqué, e as instituições formais, não incorporadas, exteriorizadas, podese admitir que as formas mesmas de cristalização das normas de conduta são importantes, diferenciando a categoria analítica das primeiras das segundas, que se caracterizam, como instituição, pelo fato do acordo geral prevalecer $^{33}$. Por outro lado, aquilo que não deveria se perder numa perspectiva interdisciplinar desse tipo é a aproximação e explicitação, pela definição ampla de instituição, daquilo que têm em comum "disposições incorporadas" e "instituições", isto é, serem ambas formas de regulação da ação coletiva (passada, presente e futura), além de deverem ser levadas em conta simultaneamente se se quiser criar um enfoque intermediário entre o holismo e o individualismo metodológicos que dê conta da dinâmica das sociedades contemporâneas.

\section{CONCLUSÃO}

Tomando como "ponto focal" a concepção "mediana" de instituição, que a vê tanto como convenção para a cooperação e forma de regu-

\footnotetext{
32 A nova economia institucional inclusive adere a essa concepção ampla de instituição: "as instituições incluem toda forma de constrangimento que os seres humanos elaboram para conformar a interação humana. As instituições são formais ou informais? Elas podem ser os dois..." (North, 1990, p. 4).

33 Por exemplo, explorando a distinção que Bourdieu faz entre os capitais culturais incorporados, institucionalizados e objetivizados (Bourdieu, 1979) porque, na medida em que cada associação é associada a um conjunto de direitos e obrigações para os indivíduos submetidos a sua ordem, o capital cultural representa diferentes formas de objetivização do conjunto desses direitos e obrigações: objetivização corporal na psiqué mesmo das pessoas, institucionalização nas organizações das quais as pessoas fazem parte, e objetivização material nas coisas que elas são chamadas a manipular e que constrangem seu modo de uso.
} 
lação de conflitos para a ação coletiva estratégica e rotineira, pode-se finalmente representar a topografia evolutiva das pesquisas institucionalistas recentes. Ela conduz a um quadro onde o conceito ideal de instituição para o qual tendem a conduzir essas pesquisas é localizado à meia distância entre, de um lado, o holismo e o individualismo metodológicos e, de outro lado, o universalismo nomológico e o culturalismo idiográfico.

BRUNO THÉRET é pesquisador do IRIS e do CNRS. Ao publicar este artigo era professor na Universidade de Paris Dauphine.

\section{REFERÊNCIAS BIBLIOGRÁFICAS}

AGLIETTA, M. (1997). "Postface", in Croissance et crises du capitalisme. Paris, Odile Jacob.

BASLE, M. (1995). “Antécédents institutionnalistes méconnus ou connus de la théorie de la régulation”, in BOYER, R. e SAILLARD, Y. (orgs.), Théorie de la régulation. L'État des savoirs. Paris, La découverte.

BILLAUDOT, B. (1996). L'ordre économique de la société moderne. Paris, L'Harmattan.

BOUDON, R. (1994). "Individualisme et holisme dans les sciences sociales", in BIRNBAUM, P. e LECA, J. (orgs.), Sur l'individualisme. Théories et méthodes. Paris, Presses de la fondation nationale des sciences politiques.

BOURDIEU, P. (1979). "Les trois états du capital culturel", in Actes de la Recherce en sciences sociales, n. 30.

BOYER, R. (1995 a). "Aux origines de la théorie de la régulation", in BOYER, R. e SAILLARD, Y. (orgs.), Théorie de la régulation. L'État des savoirs. Paris, La découverte. (1995b). "Vers une théorie originale des institutions économiques", in BOYER R. SAILLARD, Y. (orgs.), Théorie de la régulation. L'État des savoirs. Paris, La découverte. (1999). "La politique à l'ère de la mondialisation et de la finance: le point sur quelques recherches régulationnistes", in L'Année de la régulation, v. 3.

BOYER R. SAILLARD (1995). "Avant-propos", in in BOYER R. SAILLARD, Y. (orgs.), Théorie de la régulation. L'État des savoirs. Paris, La découverte.

CHARTRES, J. A (1995). "Le changement de modes de régulation. Apportes et limites de la formalisation" in BOYER R. SAILLARD, Y. (orgs.), Théorie de la régulation. L'État des savoirs. Paris, La découverte.

COBAN, A (1995). "La régulation et l'école radicale américaine", in BOYER R. SAILLARD, Y. (orgs.), Théorie de la régulation. L'État des savoirs. Paris, La découverte.

COMMONS, J. (1990). Institutional economics. Its place in political economy. New Brunswick e Londres, Transaction Books.

CORCUFF, Ph. (1999). "Le collectif au défi du singulier: en partant de l'habitus", in LAHIRE, B. (org.). Le travail sociologique de Pierre Bourdieu. Dettes et critiques. Paris, La Découverte.

CORIAT, B. (1994). "La théorie de la régulation. Origines, spécifictés et perspectives", in Futur Antérieur, número. especial, Ecole de la régulation et critique de la raison économique.

DEFALVARD, H. (1992). “Critique de l'individualisme méthodoligique revu par l'économie des conventions" in Revue économique, v. 43, n. 1. 
DIMAGGIO, P. e POWELL, W. (1997). "Le néo-institutionnalisme dans l'analyse des organisations", in Politix, n. 40, 1997.

DURKHEIM, E. (1969). Les règles de la méthode sociologique. Paris, PUF.

DUTRAIVE, V. (1995). "De l'analyse contemporaine des institutions aux institutionnalistes américains: un cheminement rétropspectif", in COREI Th. L'économie institutionnaliste. Les fondadeurs. Paris, Economica.

FAUCONNET, P. e MAUSS, M. (1901). "Sociologie" in MAUSS, M.. Oeuvres. 3. Cohésion sociale et division de la sociologie. Paris, Minuit.

FAVEREAU, O (1989). "Marchés internes, marchés externes" in Revue économique, v. 40, n. 2.

FAVEREAU, O (1995). "Conventions et régulation”, in BOYER R. e SAILLARD, Y. (orgs.), Théorie de la régulation. L'État des savoirs. Paris, La découverte.

GARRET, G. e WEINGAST, B. (1993). "Ideas, interests and institutions: constructing the European Community's internal market" in GOLDSTEIN, J e KEOHANE, R. (orgs.), Ideas and foreign policy. Beliefs, institutions and political change. Itahaca e Londres, Cornell University Press.

GISLAIN, J. J. e STEINER, Ph. (1995). La sociologie économique 1890 - 1920. Paris, PUF.

GRANOVETTER, M.. (1994). "Les institutions économiques comme construction sociales: un cadre d'analyse", in Analyse économique des conventions. ORLÉANS, A (org.). Paris, PUF.

HALL, P. e TAYLOR R. (1996). "Political science and the three new institutionalisms". Discussion Paper, 96/6.

IMMERGUT, E. (1996). "The normative roots of the new institutionnalism: historical-institutionalism and comparative policy studies" in BENZ, A e SEIBEL, W. (orgs.), Beiträge zur Theorieentwicklung in der Politik und Verwaltungswissenschaft. Baden-Baden, Nomos Verlag.

LAHIRE, B. (1999). "De la théorie de l'habitus à une sociologie psychologique" in LAHIRE, B. (org.). Le travail sociologique de Pierre Bourdieu. Dettes et critiques. Paris, La Découverte.

LORDON, F. (1999). "Croyances économiques et pouvoir symbolique” in L'Anné de la régulation, v. 3.

MATTHEWS, R. (1986). "The economics of institutions and the source of growth" in Economic Journal, 96.

MAURICE, M. (1994). "Acteurs, règles et contextes. A propos des formes de la régulation sociale et de leur mode de géneralisation" in Revue française de sociologie, 35.

(2000). "The paradoxes of societal analysis. A review of the past and prospects for the future", in MAURICE, M. e SORGE, A (orgs.). Embedding organizations. Societal analysis of actors, organizations and socio-economic context. Amsterdam and Philadelphia, John Benjamin,

NORTH, D. (1990). Institutions, institutional change and economic performance. Cambridge, Cambridge University Press.

ÓRLEAN, A (1994). "Vers un modèle géneral de la coordination économique par les conventions", in ÓRLEAN, A (org.). Analyse économique des conventions. Paris, PUF.

REYNAUD, B. (1992). Le salaire, la règle et le marché. Paris, Christian Bourgois.

STEINER, Ph. (1999). La sociologie économique. Paris, La Découverte.

THÉRET, B. (1997). "Méthodologie des comparaisons internationales, approches de l'effet sociétal et de la régulation: fondements pour une lecture structuraliste des systèmes nationaux de protection sociale", L'Anné de la régulation, v. 1.

(2000). "Theoretical problems in international comparisons. Towards a reciprocal improvemente of societal analysis and regulation theory by methodic structuralism" in MAURICE, M. e SORGE, A (orgs.). Embedding organizations. Societal analysis 
of actors, organizations and socio-economic context. Amsterdam and Philadelphia, John Benjamin.

THOENIG, J. C. (1998). "L'usage analytique du concept de régulation", in COMMAILLE, J. e JOBERT, B. (orgs.). Les métamorphoses de la régulation politique. Paris, LGDJ.

UGHETTO, P. (1999). 'Institutions et histoire, fondements communs des hétérodoxies?', Economie et Sociétés, hs, n. 35.

VARDIER, R. (2000). "Analyse sociétale et changement institutionnel: le cas de l'éducation et de la formation professionnelle", in TALLARD, M., THÉRET, B. e URI, D. (orgs.). Innovations institutionnelles et territoires. Paris, L'Harmattan.

VILLEVAL, M. C. (1995). "Une théorie économique des institutions?" in BOYER R. SAILLARD, Y. (orgs.), Théorie de la régulation. L'État des savoirs. Paris, La découverte.

WACQUANT, I e CALHOUN, C. (1989). "Intéret, rationalité et culture. A propos d'un récent débat sur la théorie de l'action" in Actes de la Recherche en Sciences Sociales, n.o 78. 


\section{RESUMOS/ABSTRACTS}

\section{AS INSTITUIÇÕES ENTRE AS ESTRUTURAS E AS AÇÕES}

BRUNO THÉRET

Considerando-se as instituições como mediações entre estruturas e comportamentos individuais, sustenta-se que é possível encontrar, tanto em Ciência Política como em Economia e Sociologia, um mesmo desenvolvimento básico do institucionalismo, dividido em três grandes correntes, cada uma com sua própria genealogia. Na teoria econômica francesa essas três correntes correspondem à teoria da regulação, à nova economia institucional e à economia das convenções. Basicamente os novos institucionalismos se diferenciam a partir de duas grandes oposições: 1) o peso que atribuem na gênese das instituições aos conflitos de interesse e de poder ou à coordenação entre indivíduos; 2) o papel que atribuem à racionalidade estritamente instrumental, ou então às representações e à cultura.

Palavras-chave: Instituições; análise institucional; neo-institucionalismo.

\section{INSTITUTIONS: BETWEEN STRUCTURES AND ACTIONS}

On the basis of a view of institutions as mediating between structures and individual behavior it is argued that the same basic development of institutionalism can be found in Political Science as well as in Economics or Sociology, according to three analytical currents, each with its own genealogy. In French economic theory these three currents correspond to the regulation theory, to the new institutional theory, and to the convention theory. Basically the new institutionalisms differ according to two great oppositions: 1) the weight given, in the genesis of institutions, either to conflicts of power and interests or to the coordination between individuals; 2) the role attributed either to a strictly instrumental rationality or to representations and culture.

Keywords: Institutions; institutional analysis; neo-institutionalism. 